University of Nebraska - Lincoln

DigitalCommons@University of Nebraska - Lincoln

Agronomy \& Horticulture -- Faculty Publications

Agronomy and Horticulture Department

2019

Selection of Bread Wheat for Low Grain Cadmium Concentration at the Seedling Stage Using Hydroponics versus Molecular Markers

\author{
Caixia Liu \\ University of Nebraska-Lincoln \\ Mary J. Guttieri \\ USDA, Agricultural Research Service, mary.guttieri@usda.gov \\ Brian M. Waters \\ University of Nebraska-Lincoln, bwaters2@unl.edu \\ Kent M. Eskridge \\ University of Nebraska-Lincoln, keskridge1@unl.edu \\ P. Stephen Baenziger \\ University of Nebraska-Lincoln, pbaenziger1@unl.edu
}

Follow this and additional works at: https://digitalcommons.unl.edu/agronomyfacpub

Part of the Agricultural Science Commons, Agriculture Commons, Agronomy and Crop Sciences Commons, Botany Commons, Horticulture Commons, Other Plant Sciences Commons, and the Plant Biology Commons

Liu, Caixia; Guttieri, Mary J.; Waters, Brian M.; Eskridge, Kent M.; and Baenziger, P. Stephen, "Selection of Bread Wheat for Low Grain Cadmium Concentration at the Seedling Stage Using Hydroponics versus Molecular Markers" (2019). Agronomy \& Horticulture -- Faculty Publications. 1273.

https://digitalcommons.unl.edu/agronomyfacpub/1273

This Article is brought to you for free and open access by the Agronomy and Horticulture Department at DigitalCommons@University of Nebraska - Lincoln. It has been accepted for inclusion in Agronomy \& Horticulture -Faculty Publications by an authorized administrator of DigitalCommons@University of Nebraska - Lincoln. 


\title{
Selection of Bread Wheat for Low Grain Cadmium Concentration at the Seedling Stage Using Hydroponics versus Molecular Markers
}

\author{
Caixia Liu, Mary J. Guttieri, Brian M. Waters, Kent M. Eskridge, and P. Stephen Baenziger^
}

\begin{abstract}
The excessive accumulation of $\mathrm{Cd}$ in harvested crops grown on high-Cd soils has increased public concerns for food safety. Due to the high consumption of bread wheat (Triticum aestivum L.) per capita, high concentrations of $\mathrm{Cd}$ in wheat grain can significantly affect human health. Breeding is a promising way to reduce grain Cd concentration. However, a lack of efficient selection methods impedes breeding for low grain $\mathrm{Cd}$ concentration in bread wheat. In this study, a recombinant inbred population segregating for grain $\mathrm{Cd}$ concentration was used to assess the efficacy of two selection methods for decreasing grain $\mathrm{Cd}$ concentration in bread wheat: a hydroponic selection method used shoot $\mathrm{Cd}$ concentration in 2-wk-old seedlings growing in Cd-containing medium, and a marker-based selection method using markers linked to heavy metal transporting P1B-ATPase 3 (HMA3), the gene underlying Cdu1. Both methods effectively selected low-Cd lines. The HMA3-linked marker-based selection was superior to hydroponic selection in terms of both simplicity and response to selection. The HMA3-linked markers explained $20 \%$ of the phenotypic variation in grain $\mathrm{Cd}$ concentration with an additive effect of $0.014 \mathrm{mg} \mathrm{kg}^{-1}$. The hydroponic selection and marker-based selection may target two different and independent processes controlling grain $\mathrm{Cd}$ accumulation, and they had no effect on grain $\mathrm{Zn}$ and $\mathrm{Fe}$ concentrations. The ALMT1-UPS4 marker associated with Al tolerance was not associated with grain Cd concentration but increased grain $\mathrm{Zn}$ and Fe concentrations. The 193-bp allele of the Rht8-associated marker, GWM261, was associated with increased grain $\mathrm{Cd}$ concentration.
\end{abstract}

C. Liu, B.M. Waters, and P.S. Baenziger, Dep. of Agronomy and Horticulture, Univ. of Nebraska-Lincoln, Lincoln, NE 68583; M.J. Guttieri, USDA-ARS, CGAHR-HWWGRU, 4011 Throckmorton Hall, Manhattan, KS 66506; K.M. Eskridge, Dep. of Statistics, Univ. of Nebraska-Lincoln, Lincoln, NE 68583. Received 9 Aug. 2018. Accepted 21 Jan. 2019. *Corresponding author (pbaenziger1@unl.edu). Assigned to Associate Editor Xiaochun Sun.

Abbreviations: ICP-MS, inductively coupled plasma-mass spectrometry; KASP, Kompetitive Allele-Specific Polymerase Chain Reaction; LOQ, limit(s) of quantitation; PCR, polymerase chain reaction; QTL, quantitative trait locus; RIL, recombinant inbred line; SNP, single nucleotide polymorphism; SSR, simple sequence repeat; STS, sequence-tagged site.

—xeessive accumulation of $\mathrm{Cd}$ in agricultural soil 1 (Zimakowska-Gnoińska et al., 2000; Han et al., 2002; Liu et al., 2005b; Rodríguez et al., 2009; Sayadi, 2014), which is the source of $\mathrm{Cd}$ to the plant, has increased concerns for food quality and safety. Exposure to $\mathrm{Cd}$ is associated with increased cancer mortality (Nishijo et al., 2006; Akesson et al., 2008; Menke et al., 2009). Estimated from a Swedish cohort, 80\% of the dietary Cd intake was from cereals and vegetables (Akesson et al., 2008). Bread wheat (Triticum aestivum L.) is widely consumed by humans, with global consumption of $67 \mathrm{~kg}$ per capita in 2016-2017 (FAO, 2016). Thus, the content of toxic elements in wheat grain can significantly affect human health. To protect consumers from excessive exposure of dietary $\mathrm{Cd}$, the maximum level of $\mathrm{Cd}$ in wheat grain is regulated at $0.2 \mathrm{mg} \mathrm{kg}^{-1}$ in Europe (The European Commission, 2006), and $0.1 \mathrm{mg} \mathrm{kg}^{-1}$ in China (USDA Foreign Agricultural Service, 2014), New Zealand, and Australia (Food Standards Australia New Zealand, 2016). Therefore, wheat breeders need to produce new cultivars to meet the changes in environmental conditions and customers' requirements (Collard and Mackill, 2008). Grain Cd concentration is affected largely by soil characteristics, yet among a set of cultivars, those with high

Published in Crop Sci. 59:945-956 (2019).

doi: 10.2135/cropsci2018.08.0484

(C) 2019 The Author(s). Re-use requires permission from the publisher. 
or low grain $\mathrm{Cd}$ concentration were consistently high or low across environments (Oliver et al., 1995; Clarke et al., 2002; Stolt et al., 2006; Guttieri et al., 2015). Therefore, it is possible to select cultivars that genetically accumulate less Cd in grain.

Although the importance of bread wheat in the human diet and the concerns about $\mathrm{Cd}$ exposure are well known, little effort has been made to breed bread wheat cultivars for low grain $\mathrm{Cd}$ concentration, in part because previous studies indicated bread wheat accumulated less $\mathrm{Cd}$ in grain than durum wheat (Triticum durum Desf.; Zook et al., 1970). Lack of low-Cd germplasm, lack of knowledge on the genetic architecture of grain $\mathrm{Cd}$ accumulation, and the inability to efficiently select low-Cd lines are the major impediments to breeding low-Cd cultivars of bread wheat. Historically, the selection of low-Cd lines in bread wheat was done using mature grain $\mathrm{Cd}$ concentration. To do so, breeders first needed to plant all the lines on high-Cd soil and harvest them at maturity. Then, grain $\mathrm{Cd}$ concentration was determined by expensive analytical instruments preceded by the digestion of grain samples using strong inorganic acid treatment (Seravalli, 2012). The disadvantages of this selection system are (i) it requires a large research field that is contaminated with $\mathrm{Cd}$ to conduct the experiment; (ii) because the grain $\mathrm{Cd}$ concentration is largely affected by environmental factors, each genotype needs to be replicated within and across sites to get an accurate estimate of the genetic potential; (iii) the selection has to be made after harvesting and completed before the next planting, which is a narrow time window in many areas (e.g., in Nebraska, about 8 to $10 \mathrm{wk}$ ); and (iv) the selection process, which involves sample digestion and mineral analysis, is hazardous, time and labor consuming, and needs expensive equipment and trained analytical experts. Thus, an efficient selection method is needed to facilitate the breeding of low-Cd cultivars.

Grain Cd concentration at maturity is positively correlated with the shoot $\mathrm{Cd}$ concentration after anthesis in rice (Oryza sativa L.) (Liu et al., 2005a, 2007), durum wheat (Chan and Hale, 2004; Greger and Löfstedt, 2004; Harris and Taylor, 2004, 2013; Wiebe et al., 2010, Arduini et al., 2014), and bread wheat (Guttieri et al., 2015). One objective of this study was to test the feasibility and efficiency of selecting low-Cd bread wheat lines using shoot $\mathrm{Cd}$ concentration in 2-wk-old seedlings in a hydroponic system. If it is feasible and efficient, breeders could use this system to eliminate the high-Cd lines before planting to better allocate the testing resources to high-priority, low-Cd lines. A hydroponic system could be a good replacement for a field experiment because (i) it can be done in a laboratory, where a large number of lines can be planted in limited space, making it more flexible and scalable than a field experiment; (ii) it needs fewer replications to remove the confounding effect of environment; and (iii) it does not need a high-Cd field site to make selections, though it still would need a small field contaminated with $\mathrm{Cd}$ to validate the hydroponic selection. Hydroponic systems have been widely used by scientists to study the uptake, translocation, and allocation of $\mathrm{Cd}$ in wheat (Chan and Hale, 2004; Van der Vliet et al., 2007; Wiebe et al., 2010; Harris and Taylor, 2013; Vergine et al., 2017).

Marker-assisted selection is preferred for traits that are difficult and expensive to phenotype and has been extensively used in plant breeding to greatly increase the efficiency of selection compared with selection based only on phenotypic data (Collard et al., 2005). An effective marker-assisted selection requires reliable markers tightly linked to quantitative trait loci (QTLs) with large effects on the trait of interest. In durum wheat, grain $\mathrm{Cd}$ concentration is controlled by a major dominant gene, Cdu1 (Clarke et al., 1997). Three Cdu1 co-segregating markers explained $>80 \%$ of the variation in grain $\mathrm{Cd}$ accumulation and were used to assist the selection of durum wheat for low grain Cd concentration (Wiebe et al., 2010). A set of single nucleotide polymorphisms (SNPs) associated with grain Cd concentration in bread wheat were identified in a region homoeologous to the Cdu1 locus in durum wheat (Guttieri et al., 2015). These markers together explained 12 to $19 \%$ of the phenotypic variation in grain $\mathrm{Cd}$ concentration in the association mapping panel where they were first identified (Guttieri et al., 2015). Based on alignment to the International Wheat Genome Sequencing Consortium reference sequence (IWGSC RefSeq v1.0), two of these SNPs were selected that span a $0.2-\mathrm{Mb}$ region of chromosome $5 \mathrm{AL}$, which includes the heavy metal transporting P1B-ATPase 3 (HMA3) (accession KF683296.1: 581,139,389-581,140,334 bp). HMA3 has been associated with major QTLs for the variation of grain $\mathrm{Cd}$ accumulation in rice (Ueno et al., 2010; Miyadate et al., 2011). OsHMA3 mediates Cd efflux into root vacuoles and thus modulates root-to-shoot translocation in rice. The $H M A 3$-flanking SNPs were successfully converted to Kompetitive Allele-Specific Polymerase Chain Reaction (KASP) markers. The KASP genotyping technology has been used across different fields because of its speed and flexibility (He et al., 2014). One objective of this study was to validate the effect of selection for the HMA3-linked markers on grain $\mathrm{Cd}$ concentration in a recombinant inbred line (RIL) population segregating for grain $\mathrm{Cd}$ concentration.

In this study, replicated selections were done in a bread wheat RIL population at seedling stage independently using two selection methods. One selection method used shoot $\mathrm{Cd}$ concentration of 2 -wk-old seedlings grown in a hydroponic system. The other selection method used $H M A 3-l i n k e d$ markers. The main objectives of this study were to assess the efficiency of each selection method on reducing mature grain $\mathrm{Cd}$ concentration and develop a breeding protocol for low-Cd bread wheat cultivars. The procedure for measuring $\mathrm{Cd}$ concentration also measured 
the concentration of other minerals (e.g., As, $\mathrm{Ca}, \mathrm{Cu}$, $\mathrm{Fe}, \mathrm{Mg}, \mathrm{Mn}, \mathrm{Ni}, \mathrm{P}$, and $\mathrm{Zn}$ ). Thus, the correlations of grain $\mathrm{Cd}$ concentration with the grain concentrations of other minerals also were evaluated in the RIL population. Interestingly, the RIL population also segregated for an Al-activated malate transporter 1 (ALMT1)-associated sequence-tagged site (STS) marker, ALMT1-UPS4, and a reduced height- 8 (Rht 8$)$-associated simple sequence repeat (SSR) marker, GWM261. Both the Al tolerance allele and reduced height allele were contributed by the high-Cd parent, 'Wesley'. Considering the association of TaALMT1 with $\mathrm{Al}^{3+}$ tolerance as a consequence of malate efflux from roots (Pineros et al., 2008), and the association of plant height with grain Cd concentration (Perrier et al., 2016), we tested the associations of these marker loci with grain mineral concentrations.

\section{MATERIALS AND METHODS Plant Material}

A population of 105 RILs $\left(\mathrm{F}_{4: 6}\right)$ derived from the cross between 'Panhandle' as female and 'Wesley' as male was used in this study. Panhandle consistently had significantly lower grain Cd concentration than Wesley (Guttieri et al., 2015). The $\mathrm{F}_{4: 5}$ RIL population initially had 120 lines and was randomly divided into three sets of 40 lines for seed increase in Yuma, AZ, but some of the lines were lost during the growing process. This resulted in $31 \mathrm{~F}_{4: 6}$ RILs in Set 1, $37 \mathrm{~F}_{4: 6}$ RILs in Set 2, and $37 \mathrm{~F}_{4: 6}$ RILs in Set 3. Later, selections were performed in these three sets independently to test the reproducibility of the selection methods.

\section{Selection Methods}

\section{Selection Using Shoot Cadmium Concentration in Two-Week-Old Seedlings}

The two parents were included in evaluations of all three sets of RILs. The selection using shoot $\mathrm{Cd}$ concentration in 2-wk-old seedlings in a hydroponic system (hereafter referenced as hydroponic selection) was performed for each set independently so that the selection procedure was replicated.

Eight seeds were randomly taken from each line (RILs and two parents). The seeds were surface sterilized for $20 \mathrm{~min}$ with $1.2 \%$ sodium hypochlorite $(6 \% \mathrm{HOCl}$, The Clorox Company) and then rinsed with ultrapure water and soaked for $2 \mathrm{~h}$ in a solution of $2 \mathrm{mM} \mathrm{CaCl}_{2}+0.001 \%$ Dividend $(7.73 \%$ difenoconazole, 1-(\{2-[2-chloro-4-(4-chlorophenoxy)phenyl]4-methyl-1,3-dioxolan-2-yl methyl)-1,2,4-triazole, $\quad 1.93 \%$ mefenoxam, methyl (2R)-2-[N-(2-methoxyacetyl)-2,6-dimethylanilino]propanoate, Syngenta Crop Protection). The seeds were then germinated for $2 \mathrm{~d}$ on germination paper well soaked with $2 \mathrm{mM} \mathrm{CaCl}+0.001 \%$ Dividend solution at room temperature in the dark. Four germinated seeds from each line, which gives $98 \%$ possibility to capture the heterogeneous lines, were transferred to $1.5-\mathrm{mL}$ centrifuge tubes (one seed in each tube) with the cap removed. The centrifuge tubes were cut open 2 to $3 \mathrm{~mm}$ from the bottom and filled with perlite beforehand. The plants were supplied with $3 \mathrm{~L}$ of chelator-buffered nutrient solutions for $2 \mathrm{wk}$ in four containers, with the RILs and two parents randomized within each container once. The nutrient solution (Wiebe et al., 2010) was prepared with ultrapure water and contained $1.0 \mathrm{mM} \mathrm{Ca}\left(\mathrm{NO}_{3}\right)_{2}, 0.3 \mathrm{mM} \mathrm{Mg}\left(\mathrm{NO}_{3}\right)_{2}, 0.3 \mathrm{mM}$ $\mathrm{NH}_{4} \mathrm{NO}_{3}, 0.25 \mathrm{mM} \mathrm{KNO}{ }_{3}, 0.1 \mathrm{mM} \mathrm{K} \mathrm{HPO}_{4}, 0.1 \mathrm{mM}$ $\mathrm{K}_{2} \mathrm{SO}_{4}, 50 \mu \mathrm{M} \mathrm{KCl}, 100 \mu \mathrm{M} \mathrm{Fe}\left(\mathrm{NO}_{3}\right)_{3}, 10 \mu \mathrm{M} \mathrm{H}_{3} \mathrm{BO}_{3}, 0.2 \mu \mathrm{M}$ $\mathrm{Na}_{2} \mathrm{MoO}_{4}, 10 \mu \mathrm{M} \mathrm{ZnSO}_{4}, 2 \mu \mathrm{M} \mathrm{CuSO}_{4}, 1 \mu \mathrm{M} \mathrm{MnSO}_{4}, 5 \mu \mathrm{M}$ $\mathrm{CdCl}_{2}, 0.1 \mu \mathrm{M} \mathrm{NiCl}_{2}, 143 \mu \mathrm{M} \mathrm{N}$-(2-hydroxyethyl) ethylenediaminetriacetic acid (HEDTA), $1.42 \mathrm{mM} \mathrm{KOH}$, and $2 \mathrm{mM}$ 2-(N-morpholino) ethanesulfonic acid (MES) buffer ( $\mathrm{pH}$ 6.0). The $\mathrm{pH}$ of the nutrient solution was adjusted to the target value of 6.0 every $2 \mathrm{~d}$. After $2 \mathrm{wk}$, the four plants from each line were carefully removed from their tubes and harvested in bulk. Their roots were washed using ultrapure water for $5 \mathrm{~min}$, soaked in $2 \mathrm{mM} \mathrm{CaCl}_{2}$ solution for $10 \mathrm{~min}$, and then washed using ultrapure water for another $5 \mathrm{~min}$. The roots and shoot were separated by cutting at approximately $1 \mathrm{~mm}$ below and $2 \mathrm{~mm}$ above the seed. Harvested tissues were placed in labeled envelopes and dried in an oven at $70^{\circ} \mathrm{C}$ for $2 \mathrm{~d}$.

After drying, the tissues were digested and the mineral concentrations were measured using the protocol as described by Guttieri et al. (2015). Briefly, samples were digested in concentrated $\mathrm{HNO}_{3}$ overnight at room temperature, followed by $1.5 \mathrm{~h}$ at $100^{\circ} \mathrm{C}$ under refluxing conditions, $1.5 \mathrm{~h}$ at $125^{\circ} \mathrm{C}$, and $2 \mathrm{~h}$ at $150^{\circ} \mathrm{C}$ after adding $\mathrm{H}_{2} \mathrm{O}_{2}$. Finally, the samples were evaporated to dryness at $165^{\circ} \mathrm{C}$. The dried residue was resuspended in $1 \%(\mathrm{w} / \mathrm{w}) \mathrm{HNO}_{3}$. Mineral concentrations in the resuspended digest were measured using an Agilent $7500 \mathrm{cx}$ inductively coupled plasma-mass spectrometry (ICP-MS, Agilent Technologies) with Ar carrier and a He collision cell at the University of Nebraska Redox Biology Center Proteomics and Metabolomics Core in Lincoln, NE. Within each set, lines were ranked by shoot $\mathrm{Cd}$ concentration from lowest to highest. Ten lines with the lowest rank were classified as low Cd lines (hereafter referenced as hydroponic low-Cd lines), and 10 lines with the highest rank were identified as high Cd lines (hereafter referenced as hydroponic high-Cd lines) (Supplemental Fig. S1). The natural log of shoot $\mathrm{Cd}$ concentrations was used for statistical analysis to improve the normality of the data.

\section{HMA3-Linked Marker Assays}

Selection using Cd-associated HMA3-linked SNP markers (Guttieri et al., 2015) (hereafter referenced as HMA3-linked marker-based selection) also was conducted for each set independently. DNA was isolated and purified from the leaves of four seedlings at 2 wk after germination for each set of RILs described above (total of $105 \mathrm{~F}_{4: 6}$ lines) plus two parents using BioSprint 96 DNA Plant Kits (Qiagen). The seedlings used for HMA3-linked marker-based selection were different subsamples of the inbred lines used for hydroponic selection. The DNA was diluted to $10 \mathrm{ng} \mu \mathrm{L}^{-1}$. The 105 lines were screened using two HMA3-linked markers (IWB43741 and IWA7579; detailed information is listed in Supplemental Table S1) derived from the 90K iSelect array (Guttieri et al., 2015) and converted to KASP, with primers obtained from IDT (Integrated DNA Technologies, Coralville, IA). Each reaction included $2.5 \mu \mathrm{L}$ of DNA template, $2.5 \mu \mathrm{L} 2 \times$ master mix (LGC), and $0.07 \mu \mathrm{L}$ $72 \times$ assay mix. The assay mix $(72 \times)$ was prepared such that the concentration of each forward primer was $12 \mu \mathrm{M}$, and the concentration of the reverse primer was $30 \mu \mathrm{M}$. The thermal 
cycling was performed on an Eppendorf Mastercycler Pro 384. The thermal cycling program was designed according to KASP genotyping chemistry user guide (https://www.lgcgroup.com/ LGCGroup/media/PDFs/Products/Genotyping/KASP-genotyping-chemistry-User-guide.pdf). The KASP assay for each SNP marker included one reaction cell for each line, three reaction cells for each parent, five reaction cells for simulated heterozygous DNA samples, and three reaction cells for nontemplate controls. The nontemplate controls used distilled water to substitute for the DNA template. Simulated heterozygous DNA samples were prepared by mixing equal amounts of DNA from each of the two parents. After polymerase chain reaction (PCR), plates were cooled to room temperature and read by FLUOstar Omega (BMG LABTECH). The SNP calling and genotype clustering were performed using the KlusterCaller data analysis software package (LGC Genomics, 2017). Lines clustered with Panhandle, Wesley, and heterozygous DNA samples were considered as low-Cd lines (hereafter referenced as HMA3-linked marker-based low-Cd lines), high-Cd lines (hereafter referenced as $H M A 3$-linked marker-based high-Cd lines), and heterogeneous lines, respectively (Supplemental Fig. S2). No recombination between the two HMA3-linked markers was observed in this RIL population. Therefore, they produced the same selection result.

\section{ALMT1-UPS4 Marker Screening}

To assess the potential effects of TaALMT1 on grain mineral concentrations, we screened our RIL population using an associated STS marker, ALMT1-UPS4. Each PCR reaction was conducted with $5 \mu \mathrm{L}$ of GoTaq green master mix (Promega), $0.3 \mu \mathrm{L}$ of each primer $(10 \mu \mathrm{M})$ (Integrated DNA Technologies, Supplemental Table S1), $1 \mu \mathrm{L}$ DNA temple (20 ng $\mu \mathrm{L}^{-1}$ ), and $3.4 \mu \mathrm{L}$ nuclease-free water (Thermo Fisher Scientific). The detail of the thermal cycling program is listed in Supplemental Table S2. The PCR products were resolved by $0.9 \%$ agarose gel electrophoresis and visualized by ethidium bromide staining using FOTO/Analyst FX (Fotodyne).

\section{GWM261 Marker Screening}

To test the association of $R h t 8$ with grain mineral concentrations, particularly $\mathrm{Cd}$, we screened our RIL population using a reduced height-8 (Rht8)-associated SSR marker, GWM261. Each PCR reaction was conducted in a volume of $10 \mu \mathrm{L}$ with $2 \mu \mathrm{L}$ of $5 \times$ GoTaq Flexi Buffer (Promega), $1 \mu \mathrm{L} \mathrm{MgCl}_{2}(25 \mathrm{mM})$, $0.2 \mu \mathrm{L}$ deoxynucleotide mix $(10 \mathrm{mM}), 0.05 \mu \mathrm{L}$ forward tailed primer $(10 \mu \mathrm{M}), 0.08 \mu \mathrm{L}$ reverse primer $(10 \mu \mathrm{M}), 0.03 \mu \mathrm{L}$ M13 dye (FAM)-labeled primer $(10 \mathrm{mM}), 0.04 \mu \mathrm{L}$ GoTaq enzyme (5 $\mathrm{U} \mu \mathrm{L}^{-1}$ ), and $6.6 \mu \mathrm{L}$ autoclaved nanopore water. The primer uences were listed in Supplemental Table S1. The detail of the thermal cycling program is listed in Supplemental Table S2. The PCR products were diluted 10-fold with water, and an aliquot was added to $\mathrm{Hi}-\mathrm{DI}$-formamide (Invitrogen) containing a labeled molecular weight ladder. After denaturation at $95^{\circ} \mathrm{C}$ for $5 \mathrm{~min}$, PCR products were electrophoresed on an Applied Biosystems Incorporated (ABI) capillary electrophoresis system. The ABI output was processed by GeneMarker (SoftGenetics; Hulce et al., 2011).

\section{Experimental Design and Phenotypic Evaluation}

Field trials were conducted during the 2015-2016 growing season at the University of Nebraska- Lincoln research farms near Mead and Clay Center, NE. Soil test data are given in Supplemental Table S3. All 105 RILs along with two parents and three other checks ('Overland', 'Freeman', and 'Ruth') and 15 bulks were randomized in two complete replicates with nested incomplete blocks of five plots in each location as an $\alpha$-lattice design. The randomization was done in AGROBASE Generation II (Mulitze, 2004). The experimental unit was a four-row plot of 1.5-m width. Plot length was measured at grain maturity and ranged from 103 to $138 \mathrm{~cm}$ in Mead and from 110 to $134 \mathrm{~cm}$ in Clay Center. The field management followed the standard agricultural practices for both locations, and each plot was sprayed with fungicide to control fungal disease. Our previous study showed that the application of fungicide has no effect on grain Cd concentration (C. Liu et al., 2018).

Mature grains were analyzed for mineral concentrations (Guttieri et al., 2015), after drying for $2 \mathrm{~d}$ in an oven at $70^{\circ} \mathrm{C}$. Limits of quantitation (LOQ) were calculated as three times the standard deviation of the concentrations of the reagent blanks, expressed on a 2.5-g grain basis (Masson et al., 2010). The concentration of $\mathrm{Ca}, \mathrm{Cd}, \mathrm{Cu}, \mathrm{Fe}, \mathrm{Mg}, \mathrm{Mn}, \mathrm{Ni}, \mathrm{P}$, and $\mathrm{Zn}$ in grain samples were always above the LOQ. Arsenic concentration was above the LOQ for $89 \%$ of the grain samples.

\section{Statistical Analysis}

Field data were analyzed by mixed effects analysis of variance for each trait using PROC GLIMMIX in SAS 9.4 (SAS Institute, 2013). Genotype, location, and genotype $\times$ location were tested as fixed effects. Block(location) and incomplete block(block, location) were tested as random effects. The effect of genotype was partitioned to the effect of checks and bulks and the effect of RILs by including a classification variable in the model, where checks and bulks were nested in Level 0 of the classification variable, and RILs were nested in Level 1 of the classification variable.

The genetic variance of the RIL population $\left(\sigma_{\text {RIL }}^{2}\right)$ and the genetic $\times$ environment variance of the RIL population $\left(\sigma_{\text {RIL } \times \text { env }}^{2}\right)$ were estimated by fitting RIL and RIL $\times$ location as random effects. The broad-sense heritability on entry-mean basis was calculated as

$$
H^{2}=\frac{\sigma_{\mathrm{RIL}}^{2}}{\sigma_{\mathrm{RIL}}^{2}+\frac{\sigma_{\mathrm{RIL} \times \mathrm{env}}^{2}}{2}+\frac{\sigma_{\text {error }}^{2}}{4}}
$$

where $\sigma_{\text {error }}^{2}$ is the residual variance. The effect of repeated selection, each selection method, and their interactions on grain $\mathrm{Cd}$ concentration were tested using ANOVA using PROC GLIMMIX in SAS 9.4 by expanding the previous model. The $104 \mathrm{df}$ of RILs was partitioned to $2 \mathrm{df}$ for set (Set 1, Set 2, and Set 3), 2 df for hydroponic selection (hydroponic high-, medium-, and low-Cd group), 2 df for HMA3-linked marker-based selection (HMA3-linked marker-based high-Cd, heterozygotes, and HMA3-linked marker-based low-Cd group), 4 df for the set $\times$ hydroponic selection, $4 \mathrm{df}$ for set $\times H M A 3$-linked markerbased selection, $4 \mathrm{df}$ for hydroponic selection $\times H M A 3-$ linked 
marker-based selection, and $6 \mathrm{df}$ for set $\times$ hydroponic selection $\times$ HMA3-linked marker-based selection, and $80 \mathrm{df}$ for RILs within set $\times$ hydroponic selection $\times H M A 3$-linked markerbased selection. The $104 \mathrm{df}$ of RIL $\times$ location was partitioned in the same way.

\section{RESULTS AND DISCUSSION The Effects of Genotype, Location, and Genotype $\times$ Location Interaction}

Analysis of variance was initially conducted for each location separately. The ratio of the residual variances from two locations (larger variance/smaller variance) was $<5$ for all the tested traits, except As concentration. Therefore, data from the two locations was combined for the ANOVA for all the traits, except As concentration. The RIL $\times$ location interaction was statistically significant for grain $\mathrm{Cd}, \mathrm{Cu}, \mathrm{Ni}, \mathrm{K}$, and $\mathrm{Zn}$ concentration, plant height, grain volume weight, and grain yield (Table 1). However, the rank correlations of genotypic least square means between Clay Center and Mead were significant $(p<0.05)$, the broad-sense heritabilities $\left(H^{2}\right)$ were $>0.5$, and the $\sigma_{\mathrm{RIL}}^{2} / \sigma_{\mathrm{RIL} \times \text { env }}^{2}$ ratios were $>1$ for all these traits (Supplemental Fig. S3). Thus, these traits had high genetic repeatability in this study, and $\mathrm{RIL} \times$ location interaction mainly changed the genotype means by magnitude, not significantly by rank. Therefore, genotypic least square means across locations were calculated for each trait. Genotypic least square means within locations were also calculated and used as appropriate.

When planted in Mead and Clay Center, respectively, 3 and 24\% of the RILs had grain Cd concentration higher than the Codex regulatory limit of $0.2 \mathrm{mg} \mathrm{kg}^{-1}$ (Fig. 1). The Cd concentration in agricultural soils in some parts of the United States could be much higher than that in our research site (Holmgren et al., 1993), and some released cultivars accumulated more $\mathrm{Cd}$ in grain than the high-Cd parent of our RIL population (Guttieri et al., 2015). Therefore, it is likely that grain $\mathrm{Cd}$ concentration of some released cultivars could exceed the regulatory limit when grown on high-Cd soil. Thus, it is necessary to breed low-Cd wheat, especially for areas contaminated with $\mathrm{Cd}$.

The higher soil Cd concentration in Mead $(0.18 \mathrm{mg}$ $\left.\mathrm{kg}^{-1}\right)$ than in Clay Center $\left(0.15 \mathrm{mg} \mathrm{kg}^{-1}\right)$ did not explain the lower grain Cd concentration in Mead than in Clay Center. To explore potential factors causing this deviation from our expectation, the Mead trial was divided into a south section (1st-15th tiers), which was waterlogged during flowering due to the high precipitation (Supplemental Table S3) and was the lower end of the field bordered by a road that acted as a dam, and a north section (16th-24th tiers). The north and south sections of the trial had a similar concentration of DTPA-extractable soil Cd before planting. Grain harvested from the south section of the Mead trial (waterlogged) had significantly lower (0.11 vs. $\left.0.18 \mathrm{mg} \mathrm{kg}^{-1}\right) \mathrm{Cd}$ concentration but higher As concentration (0.003 vs. 0.001 $\mathrm{mg} \mathrm{kg}^{-1}$ ) than grain harvested from north part of the Mead trial (less waterlogged) (Supplemental Fig. S4), which might be a result of the waterlogging condition in the south part of the field during flowering. Excess water could create a reducing soil environment, where $\mathrm{SO}_{3}{ }^{2-}$ is reduced to $\mathrm{H}_{2} \mathrm{~S}$ and may react with $\mathrm{Cd}$ to form insoluble $\mathrm{CdS}$ (Bingham et al., 1976). Although the reducing soil condition appears to have decreased bioavailable $\mathrm{Cd}$ in soil, it likely increased bioavailable As by reducing arsenate to arsenite, which is more soluble (Reynolds et al., 1999). Flooding significantly decreased grain $\mathrm{Cd}$ concentration and increased grain As concentration in rice (Arao et al., 2009; Sun et al., 2014), where 2 to $3 \mathrm{wk}$ before and after flowering were the most effective periods for reducing grain $\mathrm{Cd}$ concentration by flooding. Grain $\mathrm{Cd}$ concentration in rice was reduced by five- to sixfold by flooding during $3 \mathrm{wk}$ before heading to 3 wk after heading (Arao et al., 2009), and it was decreased by $84 \%$ by flooding from $15 \mathrm{~d}$ before heading to $25 \mathrm{~d}$ after heading (Inahara et al., 2007). Grain Cd concentration was negatively correlated with grain As concentration on plot basis ( $r=-0.54, p<2.2 \times 10^{-16}$; Supplemental Fig. S5) but

Table 1. $F$ values from the ANOVA for the effects of location (L), classification variable (CLV), CLV $\times$ location $(C L V \times L)$, checks [nested in level 0 of CLV, C(0)], check $\times$ location $[C(0) \times L$ ], recombinant inbred line [nested in Level 1 of CLV, RIL(1)], and RIL $\times$ location [RIL(1) $\times$ L] on grain mineral $(\mathrm{Ca}, \mathrm{Cd}, \mathrm{Cu}, \mathrm{Fe}, \mathrm{Mg}, \mathrm{Mn}, \mathrm{Ni}, \mathrm{P}$, and $\mathrm{Zn}$ ) concentration, plant height (hgt), grain volume weight (vw), and grain yield (yld).

\begin{tabular}{|c|c|c|c|c|c|c|c|c|c|c|c|c|c|c|c|}
\hline \multirow[b]{2}{*}{ Effect } & \multirow[b]{2}{*}{ NumDF† } & \multirow[b]{2}{*}{ - DenDF } & \multicolumn{13}{|c|}{$F$ value } \\
\hline & & & $\mathrm{Ca}$ & Cd & $\mathrm{Cu}$ & $\mathrm{Fe}$ & $\mathrm{K}$ & $\mathrm{Mg}$ & $\mathrm{Mn}$ & $\mathrm{Ni}$ & $\mathrm{P}$ & $\mathrm{Zn}$ & hgt & vw & yld \\
\hline $\mathrm{L}$ & 1 & 2 & $36.8^{*}$ & 1.4 & 0.15 & 7.8 & 5.5 & 2.53 & $615^{\star \star}$ & 0.61 & 2.3 & $57^{*}$ & 6.1 & 1.4 & 2.9 \\
\hline CLV & 1 & 2 & 0.03 & 2.1 & 2 & 0 & 0.3 & 0.37 & 2.1 & 0.06 & 1.2 & 1.1 & 14 & 0.26 & 12 \\
\hline $\mathrm{L} \times \mathrm{CLV}$ & 1 & 2 & 0.28 & 0.01 & 0.2 & 0.12 & 0.24 & 0 & 0.58 & 0.07 & 0.2 & 1.1 & 0.99 & 0.08 & 3.6 \\
\hline $\mathrm{C}(0)$ & 19 & 149 & $2.9^{\star \star \star}$ & $7.7^{\star \star \star}$ & 0.77 & $3^{\star \star \star}$ & 0.69 & 1.2 & 1.4 & $4^{\star \star *}$ & 1.6 & 1.5 & $5^{\star \star \star}$ & $5.2^{\star * \star}$ & $6.1^{\star \star *}$ \\
\hline $\mathrm{C}(0) \times \mathrm{L}$ & 19 & 149 & 0.69 & 0.7 & 0.55 & 0.85 & 1 & 1.3 & 1 & 1.2 & 0.98 & 0.45 & 0.87 & 1.2 & 1.2 \\
\hline $\mathrm{RIL}(1)$ & 104 & 149 & $3.1^{\star \star \star}$ & $6.5^{\star \star \star}$ & $3.1^{\star \star \star}$ & $2.6^{\star * \star}$ & $3.5^{\star \star \star}$ & 1.3 & $2.4^{\star \star *}$ & $6.8^{\star \star \star}$ & $1.8^{* \star \star}$ & $2.8^{\star \star \star}$ & $6.3^{* * *}$ & $11^{\star \star \star}$ & $4.9^{\star \star \star}$ \\
\hline$\underline{\operatorname{RIL}(1) \times \mathrm{L}}$ & 104 & 149 & 1.26 & $1.93^{\star \star \star}$ & $1.4^{*}$ & 1.3 & $1.5^{*}$ & 1 & 1 & $2.3^{\star \star \star}$ & 1.13 & $1.5^{\star}$ & $1.5^{\star \star}$ & $3.4^{\star \star \star}$ & $2.3^{\star \star \star}$ \\
\hline
\end{tabular}

${ }^{*},{ }^{* \star},{ }^{* * \star}$ Significant at the $0.05,0.01$, and 0.001 probability levels, respectively.

† NumDF, numerator df.

‡ DenDF, denominator df. 


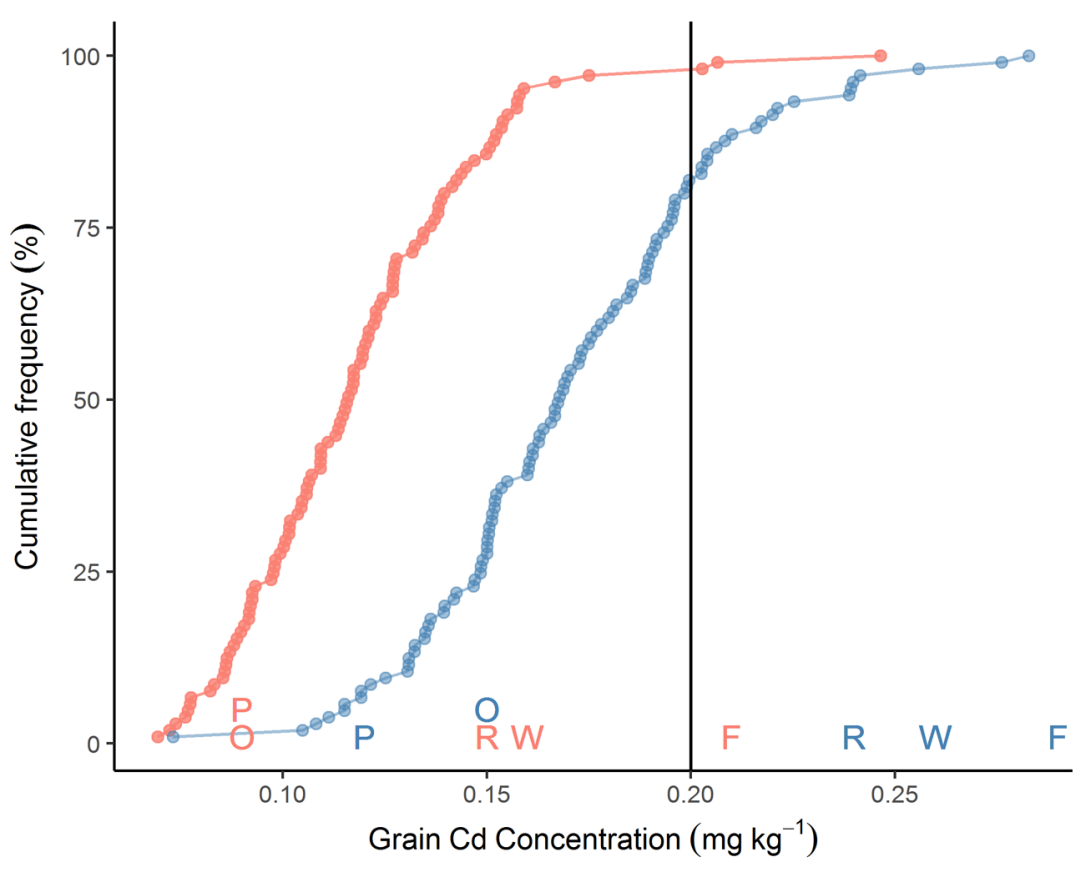

Fig. 1. Cumulative frequency of the least square means of grain Cd concentration of 105 recombinant inbred lines harvested from Mead (salmon) and Clay Center (blue). The value on the $x$ axis of "P," "O," "R," "W," and "F" present the grain Cd concentration for Panhandle, Overland, Ruth, Wesley, and Freeman, respectively, in Mead (salmon) and Clay Center (blue).

not on entry basis $(p=0.6)$ (Supplemental Fig. S6) in the Mead trial, which suggested an opposite effect of environment on grain $\mathrm{Cd}$ concentration and grain As concentration. The factor that caused this opposite effect might be waterlogging. Correlation analyses also were performed in Clay Center (Supplemental Fig. S5 and S6) to evaluate the relationship of grain $\mathrm{Cd}$ and As concentration in the absence of waterlogging. Although still significant, the negative plot basis correlation between grain Cd concentration and grain As concentration was much weaker in Clay Center $(r=$ $-0.16, p=0.012)$ than in Mead $\left(r=-0.54, p<2.2 \times 10^{-16}\right)$. Therefore, waterlogging of the south part of the Mead trial might be a potential explanation for the lower grain $\mathrm{Cd}$ concentration in Mead than in Clay Center despite the higher soil $\mathrm{Cd}$ concentration prior to planting. Because of the significant effect of soil variation on grain Cd concentration, it is important to replicate genotypes within a location to remove the effect of field variation and obtain accurate estimates of genotype effects when the trial is not homogeneous. Despite the significant location effect on grain $\mathrm{Cd}$ concentration, the rank correlation of genotypic least square means between Mead and Clay Center and the heritability for grain Cd concentration was high $(r=0.61, p<0.001$, $\left.H^{2}=0.72\right)$. This high repeatability of grain Cd concentration agrees with other studies (Kubo et al., 2008; Gao et al., 2011), and this suggests the possibility of breeding consistently low-Cd wheat cultivars across environments.

\section{Effect of Sets on Selection Results}

The selection process was replicated using three sets of RILs to test if the effect of selection is reproducible for different sets of lines. The ratio of the number of $H M A 3-$ linked marker-based low-Cd lines to the number of heterogeneous lines to the number of $H M A 3$-linked marker-based high-Cd lines (HMA3-linked markerbased low:heterogeneous:HMA3-linked marker-based high) was 16:3:12 in Set 1, 16:7:14 in Set 2, and 17:5:15 in Set 3. Thus, the RILs segregated appropriately for the SNP markers as a single locus within each set $(p>0.1)$.

To test whether our replicated selection protocols were equally effective, both selection by set interaction and set had no significant $(p>0.05)$ effect on grain Cd concentration (Supplemental Table S4). Therefore, the effect of selection on grain $\mathrm{Cd}$ concentration was reproducible with different sets of lines. Because our replicated selection protocols were equally effective in three sets, the RILs from all three sets were combined to better assess the effect on grain $\mathrm{Cd}$ concentration for both hydroponic selection and HMA3-linked marker-based selection.

\section{Effect of Hydroponic Selection on Grain Cadmium Concentration}

When grown in the field following selection, hydroponic high Cd lines had significantly $(p<0.01)$ higher average grain $\mathrm{Cd}$ concentration than the hydroponic low-Cd lines (0.165 vs. $0.144 \mathrm{mg} \mathrm{kg}^{-1}$, Fig. 2). However, there was overlap between the two groups for grain $\mathrm{Cd}$ concentration of individual field-grown lines (Fig. 2). Thus, the lines selected as low-Cd lines using the hydroponic system at seedling stage tended to, but did not always, have lower grain $\mathrm{Cd}$ concentration in the field at maturity than the lines selected as high $\mathrm{Cd}$ lines. Hydroponic selection had 

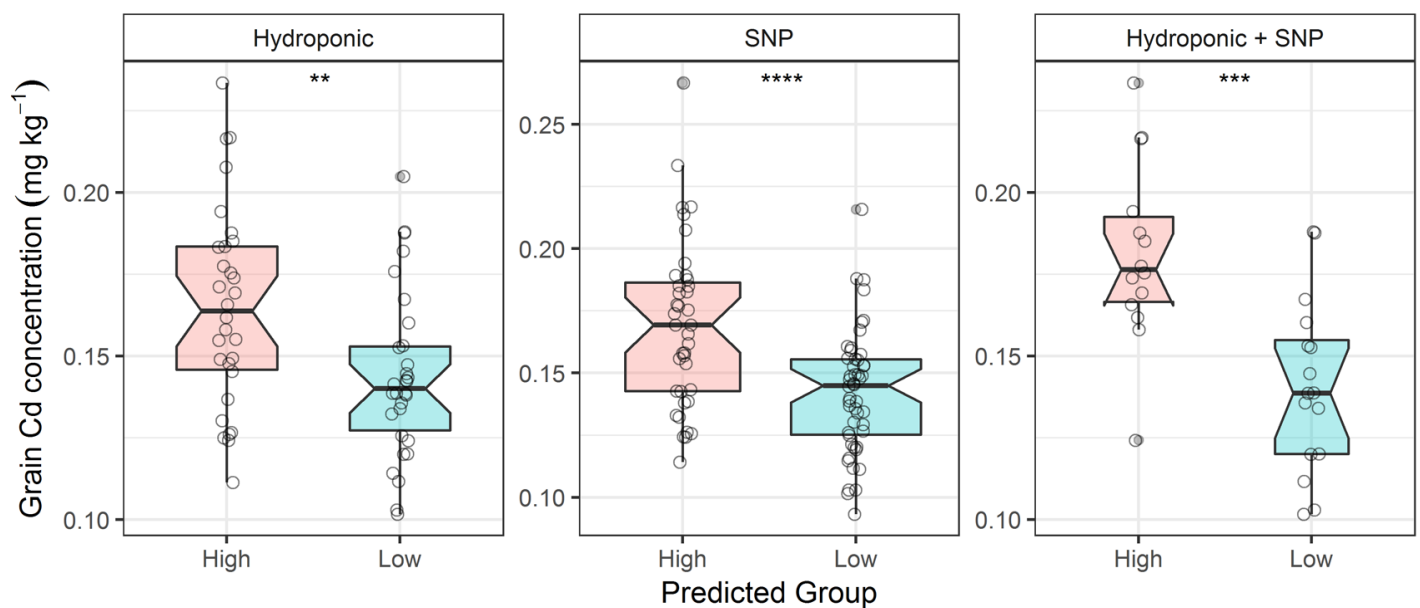

Fig. 2. Average grain $\mathrm{Cd}$ concentration in the low- and high-Cd groups selected using hydroponic selection (left panel), HMA3-linked marker-based selection (middle panel), and the combination of hydroponic and HMA3-linked marker-based selections (right panel). ${ }^{* *},{ }^{* * *}$, and ${ }^{* * * *}$ denote that the difference between the two groups is significant with $p<0.01,0.001$, and 0.0001 , respectively. SNP, single nucleotide polymorphisms.

no significant effect on other tested traits, including grain Fe and Zn concentration (Supplemental Table S5).

The selection performance may be improved by optimizing the hydroponic system. The experience from this study is that shoot $\mathrm{Cd}$ concentration separated the high- and low-Cd lines better than the root $\mathrm{Cd}$ concentration (data not shown), and that the shoot is much easier to sample than the roots. Therefore, breeders may not need to harvest the roots for making selections. Two-week-old seedlings were used for selection in this study because the time window for making selections between winter wheat harvest and subsequent planting is narrow, and in our preliminary study, shoot $\mathrm{Cd}$ concentration in 2 -wk-old seedlings growing under $5 \mu \mathrm{M}$ Cd solution effectively separated two known low Cd cultivars (Panhandle and Overland) from two known high-Cd cultivars (Wesley and Freeman). Although this system distinguished the two high-Cd cultivars well from the two low-Cd cultivars, it may not be the optimum system for making selections in large segregating populations with continuous variation. The populations used in breeding programs are generally large, ranging from hundreds to thousands of lines. Therefore, the hydroponic system could likely be further standardized and optimized using large populations to ensure its scalability and repeatability before being routinely used as a selection tool in breeding programs. Another concern with the use of hydroponic system in breeding programs is that the selection will need a large volume of nutrient media containing $5 \mu \mathrm{M} \mathrm{Cd}$, which requires careful disposal.

\section{Effect of HMA3-Linked Marker-Based Selection on Grain Cadmium Concentration}

When grown in the field after selection, the HMA3linked marker-based high-Cd lines had significantly ( $p$ $<0.0001)$ higher average grain $\mathrm{Cd}$ concentration than the HMA3-linked marker-based low-Cd lines (0.169 vs.
$0.142 \mathrm{mg} \mathrm{kg}^{-1}$, Fig. 2). Average grain Cd concentration in the heterogeneous RILs (for the HMA3-linked markers) was significantly higher than the average grain $\mathrm{Cd}$ concentration in the HMA3-linked marker-based low-Cd RILs (0.171 vs. $0.142 \mathrm{mg} \mathrm{kg}^{-1}, p<0.0001$ ), whereas it was not significantly different from the average grain Cd concentration in the $H M A 3$-linked marker-based high Cd RILs $\left(0.170\right.$ vs. $\left.0.169 \mathrm{mg} \mathrm{kg}^{-1}, p>0.05\right)$. Thus, the effect of the QTL linked to the HMA3-linked markers on grain $\mathrm{Cd}$ concentration is likely dominant, with the high-Cd allele being the dominant allele. The additive effect of the $H M A 3$-linked markers on grain $\mathrm{Cd}$ concentration was $0.014 \mathrm{mg} \mathrm{kg}^{-1}$, which is $0.47 \sigma_{\mathrm{p}}$ of the grain Cd concentration in the RIL population across two locations, where $\sigma_{p}$ is the phenotypic standard deviation. This agrees with the additive effect of 0.0008 to $0.0259 \mathrm{mg} \mathrm{kg}^{-1}$ reported in the genome-wide association study where this set of markers was first identified (Guttieri et al., 2015). The HMA3linked markers explained $20 \%$ of the phenotypic variation in grain $\mathrm{Cd}$ concentration in the RIL population. This implies the QTL linked to these markers has a large effect on grain Cd concentration, but in addition to this QTL, there may be other loci controlling grain Cd concentration in this RIL population. Except for the effect on grain Cd concentration, HMA3-linked marker-based selection had no significant effect on other tested traits, including grain Fe and Zn concentration (Supplemental Table S5).

Given the large effect of the HMA3-linked markers and the presence of other unknown QTLs controlling grain $\mathrm{Cd}$ concentration, a genome-wide selection model with the HMA3-linked marker fitted as fixed effect and the remaining markers as random effects (Bernardo, 2014) may be a useful approach to more accurately predict grain $\mathrm{Cd}$ concentration. Another advantage of genome-wide selection over using single marker only is that the genomewide selection could improve other traits concurrently 
within the population over generations, whereas the single-marker approach would be used for one generation to select lines, which will be fixed at the target locus after one generation of selection with no information on other target regions. Hence, we recommend using the HMA3linked markers for early generation selection to enrich the population for marker-based low $\mathrm{Cd}$ lines and genomewide selection in later generations.

\section{Comparison of Hydroponic and Marker- Based Selection for Selection Efficiency}

As both hydroponic selection and HMA3-linked markerbased selection were capable of distinguishing the high- and low-Cd lines, we next compared the two selection methods for their efficiency to reduce grain $\mathrm{Cd}$ concentration. Four selection strategies of keeping hydroponic low-Cd lines, discarding hydroponic high-Cd lines, keeping $H M A 3-$ linked marker-based low-Cd lines, and discarding HMA3-linked marker-based high-Cd lines were compared (Supplemental Table S6). Among the four selection strategies, the two strategies of keeping hydroponic low-Cd lines and keeping HMA3-linked marker-based low-Cd lines significantly $(p<0.05)$ reduced grain Cd concentration in the population (Supplemental Table S6). These two selection strategies resulted in a similar mean and level of variation for grain $\mathrm{Cd}$ concentration, though keeping $H M A 3-$ linked marker-based low-Cd lines had a slightly greater response. In terms of simplicity, the $H M A 3$-linked marker-based selection method takes $<1$ mo for one person to screen the RIL population (105 RILs + two parents), whereas the hydroponic selection method takes nearly 3 mo for one person to screen the RIL population (105 RILs + two parents) with continuous work. Furthermore, many breeding programs use markers for many traits, so the only additional cost might be running the KASP assay for Cd accumulation genes. Although there were advantages of the HMA3-linked marker-based selection method, the hydroponic system will remain a powerful substitution to field study for identifying low-Cd lines at the seedling stage, especially for species where breeder-friendly markers are not available or where the markers cannot explain a large proportion of the variation in grain $\mathrm{Cd}$ concentration. The increasing understanding of genetic architecture and physiological processes controlling grain $\mathrm{Cd}$ concentration and the development of technologies will help to continuously improve the efficiency of selecting low-Cd bread wheat.

\section{Developing a Better Understanding of Cadmium Accumulation in Wheat Grain}

After assessing the effect of each selection method on grain $\mathrm{Cd}$ concentration, we compared the combined effect of these two selection methods on grain Cd concentration. The $\chi^{2}$ independence test indicated that the two classification criteria, HMA3-linked marker-based and hydroponic-based, were independent from each other (Supplemental Table S7). There was a significant interaction between the two selection methods on grain $\mathrm{Cd}$ concentration (Supplemental Table S4). The two selection methods and their interactions together explained $32 \%$ of the phenotypic variation in grain $\mathrm{Cd}$ concentration. To further explore the interaction between the two selection methods, the RILs were grouped into four groups: hydroponic low and $H M A 3$-linked markerbased low (HL_ML), hydroponic low and HMA3-linked marker-based high (HL_MH), hydroponic high and HMA3-linked marker-based low (HH_ML), and hydroponic high and $H M A 3$-linked marker-based high (HH_MH). The HH_MH group had significantly higher average grain $\mathrm{Cd}$ concentration than the other three groups (Supplemental Table S8). The grain Cd concentrations of $21 \%$ of the RILs in the HH_MH group were $>0.2 \mathrm{mg} \mathrm{kg}^{-1}$, whereas grain $\mathrm{Cd}$ concentration of none of the RILs in the other three groups was $>0.2 \mathrm{mg} \mathrm{kg}^{-1}$ (Supplemental Fig. S7). Therefore, being low for either of the selection method equally and effectively regulated the accumulation of $\mathrm{Cd}$ in grain in this study.

\section{Association of the ALMT1-UPS4 Marker with Grain Mineral Concentrations}

Our RIL population also segregated for an STS marker, ALMT1-UPS4, designed from the promoter region of TaALMT1 and associated with a functional ALMT1, which confers $\mathrm{Al}^{3+}$ tolerance (Sasaki et al., 2006; Pineros et al., 2008). The upstream region of TaALMT1 was classified into six main types based on the presence of repeated blocks of sequence, and all these six upstream types could be identified using marker ALMT1-UPS4 (Sasaki et al., 2006). The Al tolerance allele was contributed by the high-Cd parent, Wesley. We screened our RIL population using ALMT1-UPS4 to assess the association between the functional allele of TaALMT1 contributed by Wesley and grain mineral concentrations.

The positive control, Wesley, amplified two strong bands of length $\sim 800$ and $\sim 1200 \mathrm{bp}$, indicating the insertion of repeated blocks in the upstream region (Sasaki et al., 2006). Another positive control, Panhandle, amplified one strong band of length $\sim 450 \mathrm{bp}$, indicating the absence of repeated blocks in the upstream region (Sasaki et al., 2006). Forty-nine RILs amplified the $~ 1200-b p$ band (hereafter denoted as the ALMT+ group), 46 RILs amplified the $\sim 450$-bp band (hereafter denoted as the ALMT- group), and 10 RILs amplified both the $\sim 1200-$ and $\sim 450$-bp bands $\left(\chi^{2}=0.9, p=0.6\right)$ (Supplemental Fig. S8). The segregation of ALMT1-UPS4 marker was independent of the HMA3-linked marker $\left(\chi^{2}=1.3, p=0.8\right)$ and our hydroponic selection result $\left(\chi^{2}=1.8, p=0.8\right)$. All the ALMT+ RILs produced extra weaker bands, which may be artifacts produced when primers and amplified 
fragments misannealed to the repeated blocks (Sasaki et al., 2006). None of the RILs amplified a strong band of length $\sim 800 \mathrm{bp}$, indicating the absence of this upstream type in the Wesley parent of this RIL population. One reason could be that Wesley is heterogeneous for ALMT1-UPS4 marker. Although the Wesley parent happens to be homozygous for this marker, the four Wesley plants combined as control DNA captured the heterogeneity of Wesley for this marker. Nevertheless, all the ALMT+ RILs produced longer band ( $\sim 1200 \mathrm{bp}$ ) than the ALMT- RILs ( $\sim 450 \mathrm{bp}$ ), indicating the presence of repeated blocks in the upstream sequence of TaALMT1 in the ALMT+ group, and the absence of repeated blocks in the upstream of TaALMT1 in the ALMT- group.

The ALMT+ and ALMT- RILs had similar grain $\mathrm{Cd}$, but ALMT+ RILs had significantly $(p<0.05)$ higher average grain $\mathrm{Fe}, \mathrm{Mg}, \mathrm{P}$, and $\mathrm{Zn}$ concentration than ALMT- RILs (Table 2, Supplemental Fig. S9). The additive effects of the ALMT1-UPS4 markers on grain $\mathrm{Fe}, \mathrm{Mg}, \mathrm{P}$, and $\mathrm{Zn}$ concentrations were $0.65,12,36.5$, and $0.5 \mathrm{mg} \mathrm{kg}^{-1}$, respectively, which were $0.24 \sigma_{\mathrm{p}}, 0.19 \sigma_{\mathrm{p}}$, $0.19 \sigma_{\mathrm{p}}$, and $0.22 \sigma_{\mathrm{p}}$ of the grain $\mathrm{Fe}, \mathrm{Mg}, \mathrm{P}$, and $\mathrm{Zn}$ concentration in the RIL population across two locations. These results suggest that the TaALMT1 Al tolerance allele on 4DL could be potentially used in breeding to increase grain $\mathrm{Fe}$ and $\mathrm{Zn}$ concentrations without affecting grain $\mathrm{Cd}$ concentration. Recent work in Arabidopsis has indicated that ALMT underpins a malate-dependent mechanism of Fe relocation in root apical meristem that is a key to root adaptation to low-P conditions (Mora-Macías et al., 2017). The role of ALMT in Fe, Mg, and $\mathrm{Zn}$ uptake in wheat merits further investigation.

\section{Association of the GWM261 Marker with Grain Mineral Concentrations}

GWM261 is an SSR marker mapped $0.6 \mathrm{cM}$ distal to Rht8 (Korzun et al., 1998), which regulates cell elongation. The 192-bp allele of GWM261 is associated with shorter parenchyma cells in peduncle and internode I (Gasperini et al., 2012). Because of the association of this marker with plant height and the potential effect of plant height (Arduini et al., 2014; Perrier et al., 2016) on grain $\mathrm{Cd}$ concentration, we screened our RIL population using
GWM261 to assess the association between this marker and grain mineral concentrations.

Wesley and Panhandle amplified the 193- (Rht8-associated) and 163-bp alleles, respectively. Forty-six RILs, forty-four RILs, and fifteen RILs amplified the 163-bp allele, 193-bp allele, and both alleles, respectively. The segregation of GWM261 marker was independent from the HMA3-linked marker $\left(\chi^{2}=0.36\right)$ and the hydroponic selection result $\left(\chi^{2}=0.16\right)$. The 193-bp allele and 163-bp allele should correspond to the commonly known 192-bp allele and 165-bp allele, respectively (Korzun et al., 1998). Hereafter, we will reference the 193-bp allele as the 192-bp allele and the 163-bp allele as the 165-bp allele.

The 192-bp allele increased the grain Cd $(0.015 \mathrm{mg}$ $\left.\mathrm{kg}^{-1}, p=0.017\right)$, Fe (1.2 $\left.\mathrm{mg} \mathrm{kg}^{-1}, p=0.06\right), \mathrm{Mg}(22 \mathrm{mg}$ $\left.\mathrm{kg}^{-1}, p=0.08\right)$, and $\mathrm{P}\left(70 \mathrm{mg} \mathrm{kg}^{-1}, p=0.1\right)$ concentrations in this RIL population across two locations (Table 2, Supplemental Fig. S10). The shorter parenchyma cells in Rht8 genotypes may have smaller vacuole for storing minerals in the stem and result in higher $\mathrm{Cd}, \mathrm{Fe}, \mathrm{Mg}$, and P concentration in grain. The GWM261 and the HMA3linked marker affected grain $\mathrm{Cd}$ concentration additively without interaction (Table 3). The RILs with both the 192-bp GWM261 allele and the high-Cd HMA3-linked marker allele had the highest average grain $\mathrm{Cd}$ concentration $\left(0.171 \mathrm{mg} \mathrm{kg}^{-1}\right)$, whereas the RILs with both the 165-bp GWM261 allele and the low-Cd HMA3-linked marker allele had the lowest average grain $\mathrm{Cd}$ concentration $\left(0.133 \mathrm{mg} \mathrm{kg}^{-1}\right)$ (Supplemental Fig. S11). These results suggest that breeders using $R h t 8$ to decrease plant height and reduce lodging may need to be particularly attentive to eliminating high-Cd alleles at the $H M A 3-$ linked locus on $5 \mathrm{~A}$.

\section{Correlation of Grain Cadmium Concentration with Other Traits}

In this RIL population, grain $\mathrm{Cd}$ concentration was positively correlated with grain $\mathrm{Cu}, \mathrm{Fe}, \mathrm{Mg}, \mathrm{Mn}$, and $\mathrm{Zn}$ concentration and negatively correlated with plant height (Supplemental Fig. S12) and was not correlated with grain yield. Studies in durum wheat showed that reduced plant height promoted $\mathrm{Cd}$ accumulation in grain, which may be due to the higher biomass accumulation in roots before

Table 2. Average grain mineral concentrations and plant height in $A L M T+$ and $A L M T-$ recombinant inbred lines (RILs) and in Rht8+ and Rht8- RILs and differences calculated as (ALMT+) - (ALMT-) and (Rht8+) - (Rht8-).

\begin{tabular}{|c|c|c|c|c|c|c|c|c|c|c|c|}
\hline Class & $\mathrm{Ca}$ & Cd & $\mathrm{Cu}$ & $\mathrm{Fe}$ & K & $\mathrm{Mg}$ & $\mathrm{Mn}$ & $\mathrm{Ni}$ & $P$ & $\mathrm{Zn}$ & Height \\
\hline & & & & & $-n$ & & & & & - & $\mathrm{cm}$ \\
\hline ALMT+ & 130 & 0.152 & 2.45 & 33 & 4466 & 1302 & 46.3 & 0.415 & 4624 & 30.4 & - \\
\hline ALMT- & 128 & 0.16 & 2.37 & 31.7 & 4481 & 1278 & 45.2 & 0.421 & 4551 & 29.3 & - \\
\hline Difference & 2 & -0.008 & 0.08 & $1.3^{*}$ & -15 & $24^{*}$ & 1.1 & 0.006 & $73^{*}$ & 1.1 * & - \\
\hline Rht8+ & 128 & 0.163 & 2.44 & 33.1 & 4472 & 1305 & 46.4 & 0.427 & 4636 & 30 & 97.9 \\
\hline Rht8- & 130 & 0.148 & 2.37 & 31.9 & 4464 & 1282 & 45.5 & 0.404 & 4567 & 29.9 & 99.5 \\
\hline Difference & -2 & $0.015^{\star}$ & 0.07 & 1.2 & 8 & $23^{*}$ & $0.9^{*}$ & 0.023 & $69^{*}$ & 0.1 & -1.6 \\
\hline
\end{tabular}

* Significant at the 0.05 probability level. 
Table 3. Analysis of variance for the effect of Rht8-associated markers and the HMA3-linked single nucleotide polymorphism (SNP) markers on grain Cd concentration $\left(\mathrm{mg} \mathrm{kg}^{-1}\right)$.

\begin{tabular}{lrcccc}
\hline Effect & df & SS† & MS $\neq$ & $\boldsymbol{F}$ value & $P$ value \\
\hline Rht8 & 2 & 0.006 & 0.003 & 4.33 & 0.016 \\
HMA3-linked SNPs & 2 & 0.017 & 0.009 & 12 & $2.24 \times 10^{-5}$ \\
Rht8:HMA3-linked SNPs & 4 & 0.005 & 0.0014 & 1.923 & 0.113 \\
Residual & 96 & 0.07 & 0.0007 & & \\
\hline
\end{tabular}

† SS, sum of squares.

$\ddagger$ MS, mean square.

heading and the higher $\mathrm{Cd}$ allocation from root to shoot after heading in short genotypes than in tall genotypes (Arduini et al., 2014; Perrier et al., 2016). Therefore, the selection of low-Cd wheat plants may unintentionally result in taller plants. In spite of the positive correlations between grain $\mathrm{Cd}$ concentration and grain $\mathrm{Fe}$ and $\mathrm{Zn}$ concentrations, the concentrations of Fe and $\mathrm{Zn}$, as well as other minerals in grain, were not significantly reduced by the HMA3-linked marker-based selection and hydroponic selection in this study (Supplemental Table S5). The TaALMT1 Al tolerance allele on 4DL was significantly and positively associated with grain $\mathrm{Zn}$ and Fe concentrations but was not associated with grain $\mathrm{Cd}$ concentration. Therefore, Zn and Fe may be regulated differently than $\mathrm{Cd}$ in this RIL population in some pathways, which provides the opportunity to decrease grain Cd concentration without affecting grain $\mathrm{Fe}$ and $\mathrm{Zn}$ concentrations.

\section{CONCLUSION}

Both hydroponic selection and HMA3-linked markerbased selection were effective in identifying high- and low-Cd lines, but the HMA3-linked marker-based selection was more effective and less time and labor consuming, especially in programs already genotyping lines. In addition, the hydroponic system may need to be optimized and standardized using additional populations to ensure its scalability and repeatability before being routinely used in breeding programs. The HMA3-linked markers explained $20 \%$ of the phenotypic variation, which may imply the presence of other QTLs controlling grain $\mathrm{Cd}$ concentration in this RIL population. Therefore, it may be worthwhile to test the efficiency of genomic selection on grain Cd concentration. Grain $\mathrm{Cd}$ concentration in bread wheat may be controlled by multiple mechanisms and the interaction among these mechanisms. The Rht 8 allele for reduced plant height was associated with increased grain $\mathrm{Cd}$ concentration, which may be a significant consideration for breeders working with Rht8 germplasm. Hydroponic selection and HMA3linked marker-based selection had no significant effect on grain $\mathrm{Zn}$ and $\mathrm{Fe}$ concentrations. The $\mathrm{Al}$ tolerance allele of ALMT1 contributed by Wesley was not associated with grain $\mathrm{Cd}$ concentration, but the Al tolerance allele increased grain $\mathrm{Zn}$ and $\mathrm{Fe}$ concentrations. It is possible to decrease grain $\mathrm{Cd}$ concentration without affecting grain $\mathrm{Fe}$ and $\mathrm{Zn}$ concentrations by using specific markers for $\mathrm{Cd}$, such as the HMA3-linked marker used in this study.

\section{Conflict of Interest}

The authors declare that there is no conflict of interest.

\section{Supplemental Material Available}

Supplemental material is available online for this article.

\section{Acnkowledgments}

The authors appreciate the help from Greg Dorn and Mitch Montgomery for their support in field and greenhouse and in managing the field trials, data collection, and harvest. This project is based on research that was partially supported by the Nebraska Agricultural Experiment Station with funding from the Hatch Act (Accession no. 0232571) through the USDA National Institute of Food and Agriculture. This project was also partially supported by Chinese Scholarship Council. The project also was partially supported by NIFA Grant 11588468. We would like to acknowledge Dr. Javier Seravalli and the University of Nebraska Redox Biology Center Proteomics and Metabolomics Core for conducting the ICP-MS assays.

Mention of trade names or commercial products in this publication is solely for the purpose of providing specific information and does not imply recommendation or endorsement by the USDA. The USDA is an equal opportunity provider and employer.

\section{References}

Akesson, A., B. Julin, and A. Wolk. 2008. Long-term dietary cadmium intake and postmenopausal endometrial cancer incidence: A population-based prospective cohort study. Cancer Res. 68:6435-6441. doi:10.1158/0008-5472.CAN-08-0329

Arao, T., A. Kawasaki, K. Baba, S. Mori, and S. Matsumoto. 2009. Effects of water management on cadmium and arsenic accumulation and dimethylarsinic acid concentrations in Japanese rice. Environ. Sci. Technol. 43:9361-9367. doi:10.1021/es9022738

Arduini, I., A. Masoni, M. Mariotti, S. Pampana, and L. Ercoli. 2014. Cadmium uptake and translocation in durum wheat varieties differing in grain-Cd accumulation. Plant Soil Environ. 60:43-49. doi:10.17221/416/2013-PSE

Bernardo, R. 2014. Genomewide selection when major genes are known. Crop Sci. 54:68-75. doi:10.2135/cropsci2013.05.0315

Bingham, F., A. Page, R. Mahler, and T. Ganje. 1976. Cadmium availability to rice in sludge-amended soil under "Flood" and "Nonflood" culture. Soil Sci. Soc. Am. J. 40:715-719. doi:10.2136/sssaj1976.03615995004000050030x

Chan, D.Y., and B.A. Hale. 2004. Differential accumulation of cd in durum wheat cultivars: Uptake and retranslocation as sources of variation. J. Exp. Bot. 55:2571-2579. doi:10.1093/ jxb/erh255

Clarke, J., D. Leisle, and G. Kopytko. 1997. Inheritance of cadmium concentration in five durum wheat crosses. Crop Sci. 37:17221726. doi:10.2135/cropsci1997.0011183X003700060008x

Clarke, J., W. Norvell, F. Clarke, and W. Buckley. 2002. Concentration of cadmium and other elements in the grain of nearisogenic durum lines. Can. J. Plant Sci. 82:27-33. doi:10.4141/ P01-083 
Collard, B., M. Jahufer, J. Brouwer, and E. Pang. 2005. An introduction to markers, quantitative trait loci (QTL) mapping and marker-assisted selection for crop improvement: The basic concepts. Euphytica 142:169-196. doi:10.1007/s10681-005-1681-5

Collard, B., and D.J. Mackill. 2008. Marker-assisted selection: An approach for precision plant breeding in the twenty-first century. Philos. Trans. R. Soc. Lond. B Biol. Sci. 363:557-572. doi:10.1098/rstb.2007.2170

FAO. 2016. Record cereal production to lift global inventories to an all-time high. FAO Cereal Supply and Demand Brief. FAO, Rome.

Food Standards Australia New Zealand. 2016. Schedule 19: Maximum levels of contaminants and natural toxicants. Food Stand. Aust. N. Z. http://www.foodstandards.gov.au/code/ Documents/Sched\%2019\%20Contaminant\%20MLs\%20 v157.pdf (accessed 28 Feb. 2019).

Gao, X., R.M. Mohr, D.L. McLaren, and C.A. Grant. 2011. Grain cadmium and zinc concentrations in wheat as affected by genotypic variation and potassium chloride fertilization. Field Crops Res. 122:95-103. doi:10.1016/j.fcr.2011.03.005

Gasperini, D., A. Greenland, P. Hedden, R. Dreos, W. Harwood, and S. Griffiths. 2012. Genetic and physiological analysis of Rht8 in bread wheat: An alternative source of semi-dwarfism with a reduced sensitivity to brassinosteroids. J. Exp. Bot. 63:4419-4436. doi:10.1093/jxb/ers138

Greger, M., and M. Löfstedt. 2004. Comparison of uptake and distribution of cadmium in different cultivars of bread and durum wheat. Crop Sci. 44:501-507. doi:10.2135/cropsci2004.5010

Guttieri, M.J., S.P. Baenziger, K. Frels, B. Carver, B. Arnall, S. Wang, et al. 2015. Prospects for selecting wheat with increased zinc and decreased cadmium concentration in grain. Crop Sci. 55:1712-1728. doi:10.2135/cropsci2014.08.0559

Han, F.X., A. Banin, Y. Su, D.L. Monts, J.M. Plodinec, W.L. Kingery, and G.E. Triplett. 2002. Industrial age anthropogenic inputs of heavy metals into the pedosphere. Naturwissenschaften 89:497-504. doi:10.1007/s00114-002-0373-4

Harris, N.S., and G.J. Taylor. 2013. Cadmium uptake and partitioning in durum wheat during grain filling. BMC Plant Biol. 13:103. doi:10.1186/1471-2229-13-103

Harris, N.S., and G.J. Taylor. 2004. Cadmium uptake and translocation in seedlings of near isogenic lines of durum wheat that differ in grain cadmium accumulation. BMC Plant Biol. 4:4. doi:10.1186/1471-2229-4-4

He, C., J. Holme, and J. Anthony. 2014. SNP genotyping: The KASP assay. Methods Mol. Biol. 1145:75-86. doi:10.1007/9781-4939-0446-4_7

Holmgren, G., M. Meyer, R. Chaney, and R. Daniels. 1993. Cadmium, lead, zinc, copper, and nickel in agricultural soils of the United States of America. J. Environ. Qual. 22:335-348. doi:10.2134/jeq1993.00472425002200020015x

Hulce, D., X. Li, T. Snyder-Leiby, and C.J. Liu. 2011. GeneMarker ${ }^{\circledR}$ genotyping software: Tools to increase the statistical power of DNA fragment analysis. J. Biomol. Tech. 22:S35-S36.

Inahara, M., Y. Ogawa, and H. Azuma. 2007. Countermeasure by means of flooding in latter growth stage to restrain cadmium uptake by lowland rice (Oryza sativa). (In Japanese.) Jpn. J. Soil Sci. Plant Nutr. 78:149-155. doi:10.20710/dojo.78.2_149

Korzun, V., M. Röder, M. Ganal, A. Worland, and C. Law. 1998. Genetic analysis of the dwarfing gene $(R h t 8)$ in wheat. Part I. Molecular mapping of $R h t 8$ on the short arm of chromosome 2D of bread wheat (Triticum aestivum L.). Theor. Appl. Genet. 96:1104-1109. doi:10.1007/s001220050845
Kubo, K., Y. Watanabe, A. Oyanagi, S. Kaneko, M. Chono, H. Matsunaka, et al. 2008. Cadmium concentration in grains of Japanese wheat cultivars: Genotypic difference and relationship with agronomic characteristics. Plant Prod. Sci. 11:243249. doi:10.1626/pps.11.243

LGC Genomics. 2017. KlusterCaller software. LGC Genomics, Herts, UK

Liu, C., M.J. Guttieri, B.M. Waters, K.M. Eskridge, A. Easterly, and P.S. Baenziger. 2018. Cadmium concentration in terminal tissues as tools to select low-cadmium wheat. Plant Soil 430:127-138. doi:10.1007/s11104-018-3712-8

Liu, J., M. Qian, G. Cai, J. Yang, and Q. Zhu. 2007. Uptake and translocation of $c d$ in different rice cultivars and the relation with cd accumulation in rice grain. J. Hazard. Mater. 143:443-447. doi:10.1016/j.jhazmat.2006.09.057

Liu, J., Q. Zhu, Z. Zhang, J. Xu, J. Yang, and M.H. Wong. 2005a. Variations in cadmium accumulation among rice cultivars and types and the selection of cultivars for reducing cadmium in the diet. J. Sci. Food Agric. 85:147-153. doi:10.1002/jsfa.1973

Liu, W., J. Zhao, Z. Ouyang, L. Söderlund, and G. Liu. 2005b. Impacts of sewage irrigation on heavy metal distribution and contamination in Beijing, China. Environ. Int. 31:805-812. doi:10.1016/j.envint.2005.05.042

Masson, P., T. Dalix, and S. Bussière. 2010. Determination of major and trace elements in plant samples by inductively coupled plasma-mass spectrometry. Commun. Soil Sci. Plant Anal. 41:231-243. doi:10.1080/00103620903460757

Menke, A., P. Muntner, E.K. Silbergeld, E.A. Platz, and E. Guallar. 2009. Cadmium levels in urine and mortality among U.S. adults. Environ. Health Perspect. 117:190-196. doi:10.1289/ehp.11236

Miyadate, H., S. Adachi, A. Hiraizumi, K. Tezuka, N. Nakazawa, T. Kawamoto, et al. 2011. OsHMA3, a $\mathrm{P}_{1 \mathrm{~B}}$-type of ATPase affects root-to-shoot cadmium translocation in rice by mediating efflux into vacuoles. New Phytol. 189:190-199. doi:10.1111/j.1469-8137.2010.03459.x

Mora-Macías, J., J.O. Ojeda-Rivera, D. Gutiérrez-Alanís, L. Yong-Villalobos, A. Oropeza-Aburto, J. Raya-González, et al. 2017. Malate-dependent Fe accumulation is a critical checkpoint in the root developmental response to low phosphate. Proc. Natl. Acad. Sci. USA 114:E3563-E3572. doi:10.1073/pnas.1701952114

Mulitze, D.K. 2004. AGROBASE Generation II user's manual. Agronomix Softw., Winnipeg, MB, Canada.

Nishijo, M., Y. Morikawa, H. Nakagawa, K. Tawara, K. Miura, T. Kido, et al. 2006. Causes of death and renal tubular dysfunction in residents exposed to cadmium in the environment. Occup. Environ. Med. 63:545-550. doi:10.1136/ oem.2006.026591

Oliver, D.P., J. Gartrell, K. Tiller, R. Correll, G. Cozens, and B. Youngberg. 1995. Differential responses of Australian wheat cultivars to cadmium concentration in wheat grain. Aust. J. Agric. Res. 46:873-886. doi:10.1071/AR9950873

Perrier, F., B. Yan, F. Candaudap, O. Pokrovsky, E. Gourdain, B. Meleard, et al. 2016. Variability in grain cadmium concentration among durum wheat cultivars: Impact of aboveground biomass partitioning. Plant Soil 404:307-320. doi:10.1007/ s11104-016-2847-8

Pineros, M.A., G.M. Cancado, and L.V. Kochian. 2008. Novel properties of the wheat aluminum tolerance organic acid transporter $\left(\mathrm{TaALMT}_{1}\right)$ revealed by electrophysiological characterization in Xenopus oocytes: Functional and structural implications. Plant Physiol. 147:2131-2146. doi:10.1104/pp.108.119636 
Reynolds, J., D. Naylor, and S. Fendorf. 1999. Arsenic sorption in phosphate-amended soils during flooding and subsequent aeration. Soil Sci. Soc. Am. J. 63:1149-1156. doi:10.2136/ sssaj1999.6351149x

Rodríguez, L., E. Ruiz, J. Alonso-Azcárate, and J. Rincón. 2009. Heavy metal distribution and chemical speciation in tailings and soils around $\mathrm{a} \mathrm{Pb}-\mathrm{Zn}$ mine in Spain. J. Environ. Manage. 90:1106-1116. doi:10.1016/j.jenvman.2008.04.007

SAS Institute. 2013. The SAS system for Windows. Release 9.4. SAS Inst., Cary, NC.

Sasaki, T., P.R. Ryan, E. Delhaize, D.M. Hebb, Y. Ogihara, K. Kawaura, et al. 2006. Sequence upstream of the wheat (Triticum aestivum L.) $A L M T_{1}$ gene and its relationship to aluminum resistance. Plant Cell Physiol. 47:1343-1354. doi:10.1093/pcp/pcl002

Sayadi, M. 2014. Impact of land use on the distribution of toxic metals in surface soils in Birjand City, Iran. Proc. Int. Acad. Ecol. Environ. Sci. 4:18-29.

Seravalli, J. 2012. Inductively coupled plasma-mass spectrometry as a tool for high-throughput analysis of plants. In: J. Normanly, editor, High-throughput phenotyping in plants: Methods and protocols. Humana Press, New York. p. 269288. doi:10.1007/978-1-61779-995-2_14

Stolt, P., H. Asp, and S. Hultin. 2006. Genetic variation in wheat cadmium accumulation on soils with different cadmium concentrations. J. Agron. Crop Sci. 192:201-208. doi:10.1111/ j.1439-037X.2006.00202.x

Sun, L., M. Zheng, H. Liu, S. Peng, J. Huang, K. Cui, and L. Nie. 2014. Water management practices affect arsenic and cadmium accumulation in rice grains. Sci. World J. 2014:596438. doi:10.1155/2014/596438

The European Commission. 2006. Commission recommendation (EC) no. 1881/2006 of 19 December 2006 setting maximum levels for certain contaminants in foodstuffs. Off. J. Eur. Union 264:5-24. https://eur-lex.europa.eu/legal-content/EN/TXT/PDF/?uri=CELEX:32006R1881\&from=ES (accessed 28 Feb. 2019).
Ueno, D., N. Yamaji, I. Kono, C.F. Huang, T. Ando, M. Yano, and J.F. Ma. 2010. Gene limiting cadmium accumulation in rice. Proc. Natl. Acad. Sci. USA 107:16500-16505. doi:10.1073/ pnas.1005396107

USDA Foreign Agricultural Service. 2014. China's maximum levels for contaminants in foods. Global Agric. Inf. Netw. Rep. CH14058. USDA Foreign Agric. Serv. https://gain.fas. usda.gov/Recent\%20GAIN\%20Publications/Maximum\%20 Levels\%20of\%20Contaminants\%20in\%20Foods\%20_Beijing_China\%20-\%20Peoples\%20Republic\%20of_12-112014.pdf (accessed 28 Feb. 2019).

Van der Vliet, L., C. Peterson, and B. Hale. 2007. Cd accumulation in roots and shoots of durum wheat: The roles of transpiration rate and apoplastic bypass. J. Exp. Bot. 58:2939-2947. doi:10.1093/jxb/erm119

Vergine, M., A. Aprile, E. Sabella, A. Genga, M. Siciliano, P. Rampino, et al. 2017. Cadmium concentration in grains of durum wheat (Triticum turgidum L. subsp. durum). J. Agric. Food Chem. 65:6240-6246. doi:10.1021/acs.jafc.7b01946

Wiebe, K., N. Harris, J. Faris, J. Clarke, R. Knox, G. Taylor, and C. Pozniak. 2010. Targeted mapping of Cdu1, a major locus regulating grain cadmium concentration in durum wheat (Triticum turgidum L. var durum). Theor. Appl. Genet. 121:1047-1058. doi:10.1007/s00122-010-1370-1

Zimakowska-Gnoińska, D., J. Bech, and F.J. Tobias. 2000. Assessment of the heavy metal pollution effects on the soil respiration in the Baix Llobregat (Catalonia, NE Spain). Environ. Monit. Assess. 61:301-313. doi:10.1023/A:1006105329210

Zook, E.G., F.E. Greene, and E. Morris. 1970. Nutrient composition of selected wheats and wheat products. 6. Distribution of manganese, copper, nickel, zinc, magnesium, lead, tin, cadmium, chromium, and selenium as determined by atomic absorption spectroscopy and colorimetry. Cereal Chem. 47:720-731. 